\title{
ESTUDO DOS HÁBITOS DE LEITURA NA COMUNIDADE ACADÊMICA DO CAMPUS ALTO PARAOPEBA DA UNIVERSIDADE FEDERAL DE SÃO JOÃO DEL-REI
}

Mateus Chaves Almeida de Oliveira

mateus.chaves@yahoo.com.br 0000-0002-6564-702X Universidade Federal de São João del Rei, Campus Alto Paraopeba, Ouro Branco, Minas Gerais.

Edmar Moreira edmar.moreira@live.com 0000-0002-0671-9863 Universidade Federal de São João del Rei, Campus Alto Paraopeba, Ouro Branco, Minas Gerais.

Raquel Gonçalves ra.goncalves3@gmail.com 0000-0002-9118-5658 Programa de Pós Graduação em Ciências Sociais. Universidade Federal de Juiz de Fora.

Gustavo Leal Toledo gustavo.leal.toledo.ufsj@gmail.com 0000-0002-5515-3042 Universidade Federal de São João del Rei, Campus Dom Bosco, Ouro Branco, Minas Gerais.Departamento de Filosofia e Métodos.

Daniela Leite Fabrino danifabrino@ufsj.edu.br 0000-0002-2740-2056 Universidade Federal de São João del Rei, Campus Alto Paraopeba, Ouro Branco, Minas Gerais. Departamento de Química, Biotecnologia e

Engenharia de Bioprocessos.

\section{RESUMO}

Na pós-modernidade, o analfabetismo funcional e o imediatismo da informação geram incapacidade interpretativa e crítica. Acreditando que estas imperícias estejam ligadas à leitura de baixa qualidade, este estudo verificou hábitos de leitura em uma amostra de 220 discentes no CAP-UFS através de um questionário. Verificou-se que 71,4\% gostam de ler (homens: $64,5 \%$; mulheres: $78,2 \%$ ). Os cursos que mais e menos gostam de ler são engenharias de telecomunicações $(77,2 \%)$ e civil $(59,2 \%)$. Não houve variação significativa no gosto pela leitura quanto à escolaridade dos pais e aceso à Internet. A frequência de leitura dos estilos é: jornais (94\%), revistas (90\%), livros/artigos acadêmicos (86\%), contos/histórias (57\%), poesias (44\%) e biografias (43\%). Textos de Internet e falta de tempo para leitura se destacaram. Assim, a falta de qualidade na leitura, gerada pela pressão fluídica pós-moderna, traduz a baixa qualidade da informação e educação. Portanto, são necessárias intervenções capazes de modificar os fatos observados.

PALAVRAS-CHAVE: compreensão da leitura, engenharia, estudo dos hábitos. 


\section{INTRODUÇÃO}

A capacidade de ler, interpretar e criticar estão relacionadas com a atuação de um povo como cidadãos plenos, portanto, tais habilidades estão intimamente ligadas ao desenvolvimento de uma determinada população (GUIMARÃES, 2010). Em um estudo da Organização para Cooperação e Desenvolvimento Econômico (OECD - sigla em inglês) foi mostrado que o brasileiro apresenta baixo grau de leitura. Ao se analisar os índices apresentados no estudo é possível perceber que o nível de leitura dos países classificados como subdesenvolvidos e emergentes está aquém daqueles praticados em países desenvolvidos. Neste estudo, o Brasil ocupou a $60^{\circ}$ posição no ranking de educação mundial (OECD, 2015). Pode-se sugerir que o mau desempenho atingido pelo Brasil no ranking da educação tenha o baixo nível de leitura como uma das causas. Segundo o Instituto Paulo Montenegro (IPM) e a ONG Ação Educativa (2012), 38\% dos estudantes brasileiros no ensino superior não dominam habilidades básicas de leitura e escrita.

Ao se discutir sobre leitura, é imprescindível abordar o analfabetismo funcional - característica atribuída a indivíduos que conseguem identificar a formação de palavras, mas não são capazes de extrair o sentido semântico de um conjunto de palavras associadas. A falta do hábito de leitura corrobora para o aumento dos níveis de analfabetismo funcional. Canabrava e Vieira (2006) mostram como o analfabetismo funcional pode ser danoso para o setor comercial. Perdas são geradas por funcionários que não conseguem entender instruções de um manual de operação e acabam por desperdiçarem tempo e matéria prima; memorandos que não são corretamente redigidos ou interpretados e fazem com que as atividades não sejam executadas como deveriam; e o não aproveitamento de informações de cursos/treinamentos por parte dos funcionários que não conseguem assimilar as informações que foram transmitidas. Tais resultados foram também verificados em crianças pelo estudo realizado por Cristofolini (2012): durante a aplicação da provinha Brasil, quando a professora realizou a leitura das questões, houve um aumento de $11 \%$ no rendimento dos alunos. Portanto, é possível constatar que a dificuldade de leitura implica na não interpretação e, consequentemente, no baixo desempenho do trabalho realizado.

O entendimento de ciência e os hábitos de leitura de uma determinada sociedade são intimamente relacionados. Estudantes de uma escola pública do ensino médio dos Estados Unidos foram divididos em dois grupos para se medir que influência o conhecimento de estratégias de leitura teria no entendimento científico dos alunos. Um grupo tinha apenas aulas de ciências e o outro, além de aulas de ciências, aulas de estratégias de leitura científica. Como resultado, o segundo grupo teve um melhor aproveitamento dos conhecimentos científicos que lhe foram propostos. Assim, compreende-se que o entender cientifico está intimamente ligado a leitura. Ser capaz de argumentar, entender as bases e consequências de debates ou estudos e ser hábil a construir o conceito em entendimento e fazer uso da vigilância epistêmica estão entrelaçados com a habilidade de leitura de um indivíduo (WELLINGTON e OSBORNE, 2001; YORE, 2004).

Ao mesmo tempo em que se verifica a necessidade da capacidade crítica para a ampla absorção dos conceitos envolvidos em um texto (YORE, 2004), 
observa-se o imediatismo da informação (BAUMAN, 2001). Ambas as características são usadas para descrever a sociedade pós-moderna. Neste tipo de sociedade, a escola vem perdendo terreno para outras instâncias no processo educativo e percebe-se a fuga da racionalidade lógica e unidirecional (características da modernidade) para uma racionalidade que cria no diálogo os pontos de apoio de sua validade ao mesmo tempo em que se tem pouco preparo para a execução desta nova racionalidade (VEIGA-NETO, 2008; BERNADETE, 2005). Fazendo-se necessária a disseminação das habilidades ligadas à interpretação e crítica, principalmente dentro do meio acadêmico.

Desta forma, o hábito da leitura dentro da universidade tem sido assunto de debate colocado por muitos pesquisadores e estudiosos. Diversos autores têm destacado o fato de que um dos principais objetivos do ensino é a formação de pessoas capazes de absorver e compreender adequadamente tudo aquilo que Ihes é apresentado. Assim, a leitura pode ser considerada a atividade mais importante do meio acadêmico, pois interfere diretamente no rendimento dos discentes (OLIVIERA, 1996). Rodrigues et al. (2014) mostraram que programas de intervenção que disseminem estratégias cognitivas e metacognitivas de leitura com o objetivo de potencializar a compreensão são necessários e apresentam bons resultados no ambiente acadêmico.

Em especial, os alunos de engenharia recebem destaque por apresentarem grande aptidão pela área de exatas e, assim, pouco interesse ou perícia na leitura e interpretação. Tal fato foi verificado pelos professores dos cursos de engenharia do campus Alto Paraopeba da Universidade Federal de São João delRei (CAP - UFSJ), que apresentaram queixas relacionadas à capacidade dos alunos de ler e interpretar. Em uma consulta realizada com representantes de todos os departamentos da referida instituição, verificou que 43,2 \% dos docentes classificam como ruim a capacidade gramatical, $62,2 \%$ classificam como ruim o nível semântico e 56,8 \% classificam como ruim o nível de interpretação dos discentes do campus. Na mesma consulta, apenas 10,8; 2,7 e 5,4 \% classificaram como bons os respectivos níveis. Fica evidente a baixa capacidade de ler, interpretar e criticar dos alunos.

O fato observado pela consulta realizada junto aos professores do CAP UFSJ pode estar relacionado ao contato literário adquirido durante a vida destes estudantes. Segundo Yunes (2002) e Eugênio et al. (2012), a má instrução da leitura no início da vida e a falta de contato com música podem acarretar maior dificuldade de compreensão e interpretação dos materiais usados na universidade, influenciando, consequentemente, no desenvolvimento social dos discentes.

O estudo aqui proposto visa avaliar os hábitos de leitura dos estudantes do campus Alto Paraopeba da Universidade Federal de São João del-Rei(CAP-UFSJ). Localizado na cidade de Ouro Branco, Minas Gerais, o campus é composto por cinco cursos de engenharia (bioprocessos, civil, mecatrônica, química e telecomunicações). Tal estudo foi conduzido pelo grupo de leitura do Programa de Educação Tutorial "A Difusão do Pensamento Cientifico como Ferramenta para Cidadania" (PET-DPCFC), modalidade Conexões dos Saberes. O grupo de leitura do PET-DPCFC visa ampliar a oportunidade de contato dos alunos de todos os cursos do campus com gêneros de leitura não acadêmicos. Desse modo, em média, dois livros são escolhidos por semestre e discussões sobre os mesmos são realizadas para que diferentes visões e interpretações das histórias sejam 
compartilhadas de forma a estimular o senso crítico dos alunos que compõem o grupo.

Como citado previamente, o número de brasileiros que leem é relativamente baixo, se comparado aos dos países desenvolvidos. Sendo assim, parece coerente supor que estes indivíduos possivelmente componham o ensino superior público. O estudo aqui apresentado tenta estabelecer causas e implicações da prática de leitura em um nicho local (CAP-UFSJ). Uma análise quantitativa e qualitativa do público-alvo, assim como mapeamento de seu perfil foi realizada através de um questionário visando fortalecer as hipóteses levantadas, o questionário é descrito com detalhes na metodologia. Posteriormente, os dados são analisados e os resultados dos mesmos discutidos. Por fim, na conclusão é apresentado se as hipóteses do trabalho foram confirmadas e sugestões de mais estudos sobre o tema são propostas.

\section{Metodologia}

A presente pesquisa tem um caráter exploratório que busca investigar a prática de leitura dos alunos da Universidade Federal de São João del Rei do Campus Alto Paraopeba (UFS - CAP), localizada na cidade de Ouro Branco, Minas Gerais, onde foi aplicado questionário - apresentado no Anexo I - junto a 220 alunos divididos igualmente entre os cinco cursos de engenharia do campus (bioprocessos, civil, mecatrônica, química e telecomunicações). Diversos horários, locais e modos de abordagem foram usados para que as amostras coletadas pudessem ser representativas em relação ao total de alunos engajados nos cursos.

Para que o perfil de leitura dos entrevistados fosse construído, o questionário foi dividido em três partes principais. A primeira envolve a identificação do aluno como pessoa dentro da instituição e na sociedade. É composta, principalmente, por questões que exigem respostas rápidas e intuitivas, pois estão relacionadas a condições bem definidas da vida do estudante. Primeiramente, tentou-se fazer distinção entre os sexos, com a intenção de observar se essa variável influenciava no gosto pela leitura, ou seja, se há uma diferenciação dentre homens e mulheres com maior ou menor hábito de leitura. Seguindo o mesmo objetivo, foram feitas as distinções dos entrevistados a partir dos cursos, escolaridade do pai e da mãe. Outra dimensão abordada foi a preferência por outras fontes de lazer frente à leitura e ao acesso à Internet, acreditando que a dificuldade de ter contato com o mundo digital pode ser uma barreira ou incentivo para possíveis leitores.

A segunda parte do questionário possui perguntas que objetivam identificar os hábitos de leitura dos participantes. É composta por questões cuja resposta é menos intuitiva e depende do gosto individual. A pergunta que se destaca pela sua importância, devido o objetivo do projeto que esse trabalho é fruto, é a oitava "Você gosta de ler?". Ela é feita antes mesmo que as demais questões de identificação sejam propostas para evitar que ocorra uma mudança de opinião durante o preenchimento do questionário. Na questão 17 intenta-se verificar se o gosto ou não gosto, especificado na questão 8 , é efetivado em leitura. Caso ele seja, esta questão também pretende definir a frequência com que cada tipo de 
leitura é realizada. Finalmente, a questão 20 permite identificar os empecilhos à atividade.

A terceira e última parte do questionário envolve dois tipos principais de perguntas: aquelas que são usadas para direcionar o participante em uma linha de pensamento que o permita responder mais fielmente às questões relacionadas à segunda parte do questionário e aquelas relacionadas ao conhecimento e participação do Grupo de Leitura CAP. Estas questões por conterem respostas não objetivas podem ser analisadas em um futuro trabalho.

Após a produção dos dados, as respostas foram transcritas e tratadas no programa Excel ${ }^{\circledR}$. Os resultados obtidos serão apresentados na próxima seção.

\section{Resultados e Discussão}

O questionário desenvolvido pelo Grupo de Leitura CAP buscou investigar a prática de leitura dos alunos da UFSJ-CAP. Para isso, diferentes abordagens foram realizadas de forma que os perfis analisados fossem o mais abrangente possível. De forma geral, o questionário mostrou que $71,4 \%$ dos alunos declararam gostar de ler. Porém, os fatores que podem diferenciar estes números serão analisados mais profundamente.

Conforme descrito na seção de metodologia, o primeiro parâmetro analisado foi à diferença do gosto de leitura entre o sexo dos candidatos. O resultado obtido através do questionário é mostrado na Tabela 1.

Tabela 1 - Gosto pela leitura de acordo com o sexo.

\begin{tabular}{ccc} 
Parâmetro & Masculino (\%) & Feminino (\%) \\
\hline Gosta de Ler & 64,5 & 78,2 \\
Não Gosta de Ler & $35,5$. & 21,8
\end{tabular}

Conforme pode ser observado através da Tabela 1 , o sexo feminino apresenta uma taxa de gosto pela leitura de aproximadamente 14 pontos percentuais acima do sexo masculino. Este resultado será usado como ponto de partida para a discussão dos demais resultados apresentados.

O segundo parâmetro utilizado para identificar os alunos quanto ao gosto pela leitura foi o curso. O CAP-UFSJ apresenta cinco opções diferentes de cursos de engenharia. A Tabela 2 apresenta os resultados obtidos para a consulta do gosto de leitura conforme o curso de engenharia. 
Tabela 2 - Gosto pela leitura de acordo com o curso de Engenharia do CAP - UFSJ.

\begin{tabular}{cccccc} 
Parâmetro & $\begin{array}{c}\text { Bioprocessos } \\
\text { (\%) }\end{array}$ & $\begin{array}{c}\text { Civil } \\
\text { (\%) }\end{array}$ & $\begin{array}{c}\text { Mecatrônica } \\
\text { (\%) }\end{array}$ & $\begin{array}{c}\text { Química } \\
\text { (\%) }\end{array}$ & $\begin{array}{c}\text { Telecomuni- } \\
\text { cações (\%) }\end{array}$ \\
\hline $\begin{array}{c}\text { Gosta de } \\
\text { Ler }\end{array}$ & 74,5 & 59,2 & 64,7 & 73,7 & 77,2 \\
$\begin{array}{c}\text { Não Gosta } \\
\text { de Ler }\end{array}$ & $25,5$. & 40,8 & 35,3 & 26,3 & 22,8 \\
& & & & &
\end{tabular}

A média observada para os cursos é de 69,8 com desvio padrão de $\pm 7,6$. Sendo assim, o único curso que apresenta valores para o gosto pela leitura inferior à média e desvio padrão é o de Engenharia Civil.

Observa-se que, dentro da margem dos resultados, os alunos do curso de Engenharia Mecatrônica são os que menos gostam de ler. Parte deste fato pode ser justificado pela presença massiva de alunos do sexo masculino que gostam menos de ler conforme foi constatado e apresentado na Tabela 1. Por outro lado, o curso de Engenharia de Telecomunicações apresenta a maior quantidade de alunos que declaram gostar de leitura. Mesmo estando dentro da margem de erro, o resultado do curso de Engenharia de Telecomunicações chama a atenção por estar bem próximo ao valor máximo dentro desta margem.

Apesar de não serem conclusivos, os resultados mostrados na Tabela 2 indicam que não há nenhum curso do CAP/UFSJ no qual o gosto pela leitura representa menos que $50 \%$ dos entrevistados. Desta forma, torna-se inviável a afirmação de que o desgosto pela leitura seja a causa da dificuldade de interpretação verificada pelos professores dentro da instituição em estudo. Por outro lado, é importante que outros parâmetros sejam avaliados para verificar se o gosto é efetivamente transformado em hábito de leitura. Caso isso ocorra, a hipótese de que a dificuldade de interpretação é consequência da baixa taxa de leitura poderia ser questionada.

Segundo Molina (1992),

\begin{abstract}
Este é, a nosso ver, o pecado capital da escola pública mal direcionada: assume o compromisso pela metade. Os alunos chegam a ler, mas apenas decodificando os textos, sem alcançar a compreensão verdadeira nem, muito menos, a capacidade de crítica. Iludem-se com o que leem, porque está impresso, aceitam tudo que veem escrito, não são autônomos diante do texto.
\end{abstract}

Usando a argumentação de Molina (1992) anteriormente citada, é possível acrescentar a possibilidade de que os discentes não só gostam de ler, como também, realizam esta atividade. Porém, não possuem habilidades suficientes para interpretar e criticar, "não são autônomos perante o texto". Assim o autor reforça a argumentação da existência de que o problema não está apenas na falta de leitura, mas sim na dificuldade de interpretação e análise do texto lido. Essas são características bem conhecidas do analfabetismo funcional, mal que se instaurou na sociedade brasileira e que é responsável por grandes perdas na economia das empresas que contam com profissionais incapazes de serem autônomos frente ao texto (CANABRAVA e VIEIRA, 2006). Conforme foi comentado por um dos docentes envolvidos na consulta realizada no CAP - UFSJ, "a longo prazo, é preocupante que profissionais que não conseguem interpretar textos de 2 parágrafos (...) para a resolução de um problema entrem no mercado 
(de trabalho)". Em contrapartida, outro docente acredita que "talvez isso ocorra mais por preguiça e falta de hábito em se aprofundar em textos mais longos que por falta de conhecimento da língua". Em todos os casos, fica evidente a necessidade de implantação de medidas que possibilitem romper com esta barreira e vencer a possível instalação do analfabetismo funcional nas instituições de ensino (RODRIGUES et al., 2014).

De acordo com Piccolo et al., (2012) e Lúcio et al., (2010), alguns fatores sociais, tais como escolaridade dos pais e acesso à Internet, podem influenciar no gosto pela leitura. Portanto, este estudo buscou estabelecer qual a influência destes fatores no hábito de leitura dos participantes. A Tabela 3 apresenta os resultados obtidos para a consulta do gosto de leitura conforme a escolaridade dos pais.

Tabela 3 - Gosto pela leitura de acordo com a escolaridade dos pais

\begin{tabular}{ccccc} 
Parâmetro & $\begin{array}{c}\text { Fundamental } \\
\text { Incompleto } \\
(\%)\end{array}$ & $\begin{array}{c}\text { Médio } \\
\text { Incompleto } \\
(\%)\end{array}$ & $\begin{array}{c}\text { Superior } \\
\text { Incompleto } \\
\text { (\%) }\end{array}$ & $\begin{array}{c}\text { Superior } \\
\text { Completo } \\
\text { (\%) }\end{array}$ \\
\hline $\begin{array}{c}\text { Gosta de } \\
\text { Ler }\end{array}$ & 75 & 68 & 73,1 & 68 \\
$\begin{array}{c}\text { Não Gosta } \\
\text { de Ler }\end{array}$ & 25 & 32 & 26,9 & 32 \\
& & & &
\end{tabular}

A média observada para o gosto de leitura com relação à escolaridade dos pais é de $71,0 \pm 3,6$. Sendo assim, o único grupo que apresenta valores para o gosto pela leitura além da margem dos resultados é aquele cujos pais têm média de escolaridade igual ao fundamental incompleto. Porém, a diferença entre a quantidade daqueles que declaram gostar de leitura e o limite máximo da margem dos resultados é de apenas 0,4 pontos percentuais.

Com os dados levantados, não é possível chegar à conclusão de como o nível de escolaridade dos pais influencia no processo de desenvolvimento de gosto pela leitura. Os grupos que apresentam os dados mais extremos são aqueles cujos pais têm escolaridade média igual ao fundamental incompleto e ao superior completo.

Os alunos cujos pais têm escolaridade média igual ao fundamental incompleto são os que apresentam maior gosto pela leitura. Um dos possíveis motivos levantados para a justificativa deste resultado é que tais alunos busquem na educação uma alternativa de vida que seja mais estável que aquela que foi proporcionada por seus pais. Os alunos cujos pais apresentam escolaridade média igual ao superior completo e que provavelmente tiveram uma média salarial maior do que aquela dos pais cuja média corresponde ao fundamental incompleto apresentam menor gosto pela leitura. Da mesma forma, porém no sentido inverso, é possível levantar a hipótese de que tal falta de interesse esteja ligada ao fato de que a busca pela educação não vai de encontro com o almejo de uma situação financeira mais estável que aquela proporcionada pelos pais.

É importante ressaltar que as hipóteses levantadas na discussão anterior não podem ser comprovadas pelo presente estudo uma vez que não há dados financeiros no questionário que foi aplicado. Mas estas hipóteses podem ser levantadas com base na informação que, de forma geral, a média salarial de uma família cuja média de escolaridade é maior tende a ser maior, também. 
A Tabela 4 apresenta o resultado para a pesquisa realizada sobre outro fator social: acesso à Internet.

Tabela 4 - Gosto pela leitura e acesso à Internet

\begin{tabular}{ccc} 
Parâmetro & $\begin{array}{c}\text { Acesso à } \\
\text { Internet (\%) }\end{array}$ & $\begin{array}{c}\text { Sem acesso à } \\
\text { Internet (\%) }\end{array}$ \\
\hline $\begin{array}{c}\text { Gosta de } \\
\text { Ler }\end{array}$ & 71,4 & 100 \\
$\begin{array}{c}\text { Não Gosta } \\
\text { de Ler }\end{array}$ & 28,6 & 0
\end{tabular}

Os dados da Tabela 4 apresentam, quando avaliados sozinhos, uma dependência enorme do gosto de leitura pela falta de acesso à Internet - uma vez que todos aqueles que não possuem acesso à rede declaram gostar de ler, enquanto $28,6 \%$ dos que possuem acesso à Internet declaram não gostar de ler. No entanto, a análise não pode ser conduzida neste sentido, pois o número de participantes que não possuem acesso à Internet não é representativo para a amostragem: apenas 4 dos entrevistados não possuía acesso à rede mundial de computadores.

A próxima análise realizada com os dados do questionário está relacionada às barreiras à leitura. $O$ gráfico da Figura 1 mostra os resultados obtidos das entrevistas.

Figura 1 - Barreiras frente ao hábito da leitura

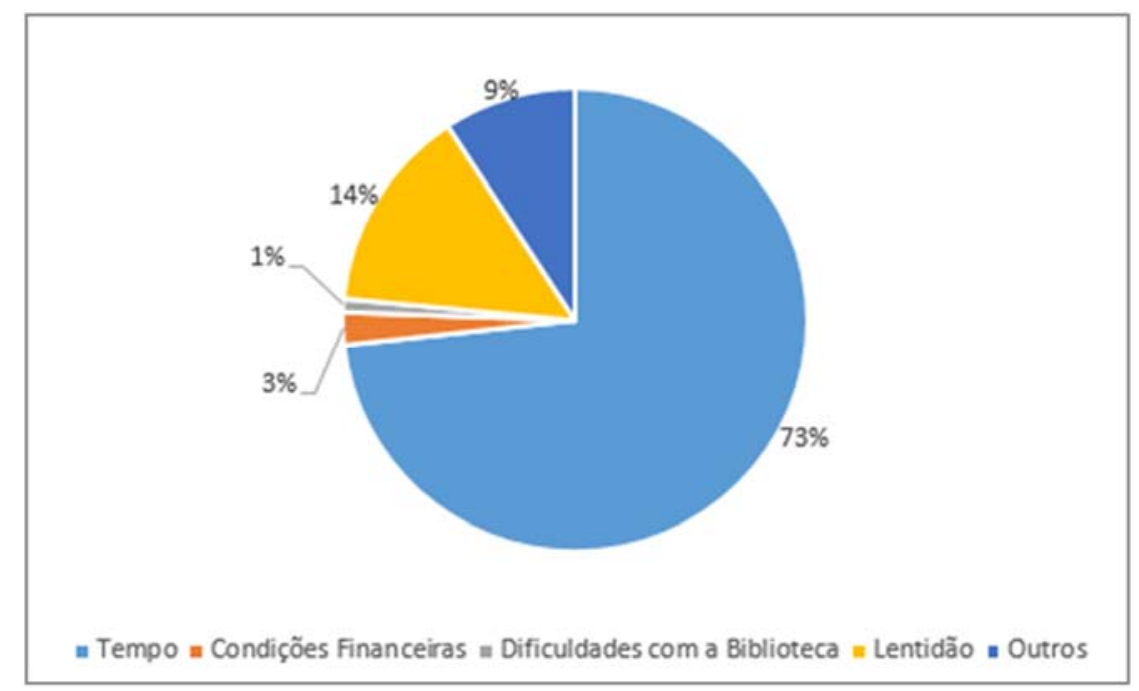

(Fonte: dados da pesquisa)

A principal dificuldade apontada pelos universitários participantes da pesquisa para a transformação do gosto pela leitura no hábito propriamente dito foi o tempo. De acordo com $73 \%$ dos participantes, a falta de tempo hábil é o gargalo para a leitura. $\mathrm{O}$ tempo apresenta um índice mais que cinco vezes maior em relação ao segundo obstáculo mais citado: a lentidão na leitura. Contudo, esses dois principais empecilhos apresentados podem ser entendidos em conjunto, à medida que a lentidão na leitura é uma característica do processo, o tempo se torna um problema até mesmo para aqueles que dispõem de certa quantidade deste. 
A condição financeira foi mencionada por 3\%, este é um fator que pode influenciar principalmente a leitura de obras novas e que ainda não estão dispostas em bibliotecas públicas.

Dado que a maioria dos alunos $(71,4 \%)$ respondeu positivamente quanto ao gosto pela leitura, dois fatores principais devem ser analisados: "este gosto pela leitura é efetivamente transformado na atitude de ler?" Caso a resposta seja afirmativa, "quais estilos textuais são lidos?" Portanto, o próximo parâmetro que foi analisado no presente estudo é o tipo de leitura.

Os textos literários foram divididos em sete categorias: biografias, contos e histórias, jornal impresso, livros e artigos acadêmicos, poesia, revista e textos na Internet. Os gráficos da Figura 2 mostram a frequência de leituras destas categorias exceto textos de Internet.

Figura 2 - Gráficos da frequência de leituras nas categorias: (a)biografia; (b)contos e histórias; (c)jornal impresso; (d)livros e artigos acadêmico; (e)poesias; (f)revistas

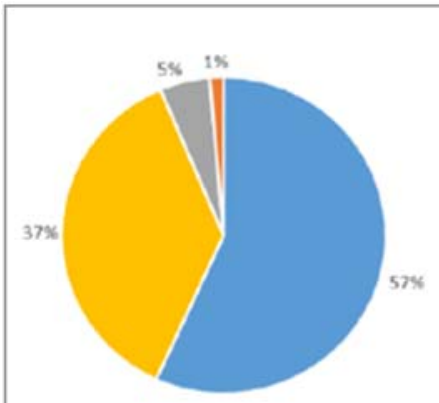

(a)

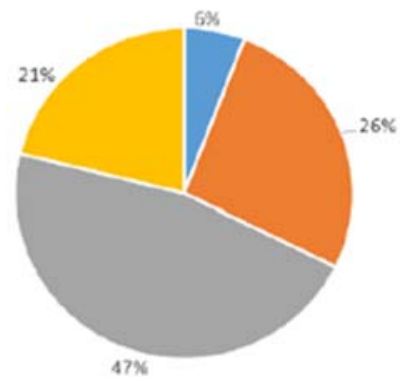

(c)

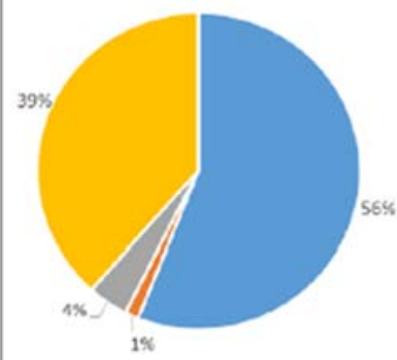

(e)

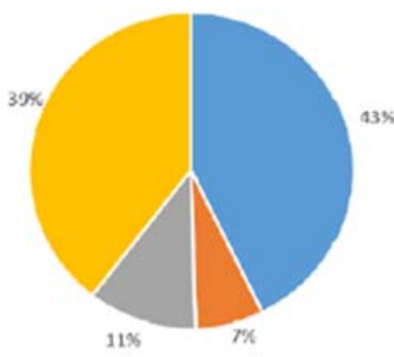

(b)

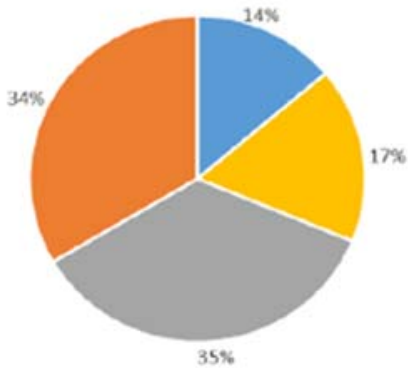

(d)

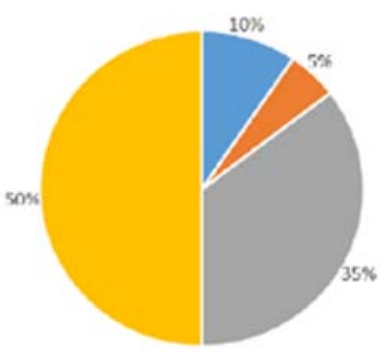

(f)

" Nãolê = Diariamente | Semanalmente = Mensalmente

(Fonte: dados da pesquisa) 
Através da análise da Figura 2 (a) é possível perceber que mais da metade dos entrevistados não leem biografias $(57,0 \%)$ e a maior parte dos que o fazem é mensalmente $(37,0 \%)$. Este resultado mostra que livros do tipo biográficos não atraem a maioria do público participante da pesquisa: alunos de engenharia do CAP-UFSJ.

A Figura 2 (b) mostra que a maioria dos participantes da pesquisa afirma que não leem contos e histórias $(43,0 \%)$ e os $39,0 \%$ que fazem esse tipo de leitura apresentam uma frequência mensal. Porém, percebe-se que contos e histórias são mais lidos que biografias $(57,0 \%$ x 43,0\%), mesmo que em frequências ainda baixas. Da mesma forma, este resultado mostra que livros do tipo contos e histórias não atraem grande parte do público participante da pesquisa: alunos de engenharia do CAP-UFSJ.

Ao contrário do que foi observado para as categorias de textos bibliográficos e contos e histórias, a leitura de jornal impresso é realizada por grande parte dos participantes da pesquisa $(94,0 \%)$, conforme pode ser observado pela Figura 2 (c). Deste total, a maioria lê semanalmente $(47,0 \%)$, mas o número de leitores diários deste tipo de texto é alto $(26,0 \%)$ e supera o número de leitores mensais $(21,0 \%)$. Este resultado mostra que textos do tipo jornalístico são comumente lidos pelo público pesquisado.

Tal resultado pode ser justificado pela conexão dos estudos de engenharia com o desenvolvimento econômico e tecnológico, cuja principal forma de divulgação são os jornais, dentre eles, os impressos. É importante perceber também, que a leitura de jornais implica em investimento em conhecimento de atualidades, habilidade que também é requerida de engenheiros, principalmente em processos seletivos para estágio e trainee - as principais ambições dos alunos que se aproximam da graduação.

Através da análise da Figura 2 (d) é possível observar que a grande maioria dos participantes da pesquisa leem livros e artigos acadêmicos (86,0\%). Destes, aproximadamente $40,0 \%$ leem este tipo de texto diariamente ( $34,0 \%$ do total) e outros $41,0 \%$ leem semanalmente $(35,0 \%$ do total). Estes resultados já eram esperados uma vez que a pesquisa foi realizada dentro de um centro de educação. Por outro lado, é surpreendente que $14,0 \%$ dos participantes tenham declarado não fazer a leitura de livros e artigos acadêmicos, uma vez que estes são a base para o ensino de qualquer disciplina nas mais diversas áreas do conhecimento.

Os resultados obtidos da análise destes dados podem ser um indicativo da frequência de estudos dos alunos do CAP - UFSJ. Porém, deve-se notar que os estudos não se baseiam apenas em livros e artigos acadêmicos, muitos alunos declaram estudar apenas notas de aulas apresentadas pelos professores.

Ao analisar os dados fornecidos na Figura 2 (e), nota-se que o gênero poético é muito pouco apreciado pelos alunos dos cursos de engenharia do CAP-UFSJ, dos quais $56,0 \%$ declaram não ler este tipo de texto. Da mesma forma, 39,0\% fazem a leitura mensal e apenas 1,00\% lê este tipo de texto diariamente.

Os dados do gráfico da Figura 2 (f) mostram que o gênero de revistas é lido por grande parte dos entrevistados $(90,0 \%)$, sendo superado em número de leitores apenas pelo gênero jornal impresso. $50,0 \%$ do total de entrevistados leem este tipo de texto mensalmente e $35,0 \%$ leem semanalmente. Dado que a 
maioria destes periódicos é publicada semanalmente ou mensalmente, há condições de que a leitura seja realizada de acordo com o lançamento de novas publicações. Para um gênero literário que é publicado semanalmente ou mensalmente, apresentar $5,00 \%$ de leitores diários não representa um fator que pode ser interpretado como rejeição por parte do público.

Finalmente, o gráfico da Figura 3 mostra a frequência de leituras na categoria de textos na Internet.

Figura 3 - Frequência de leituras na categoria de textos na Internet

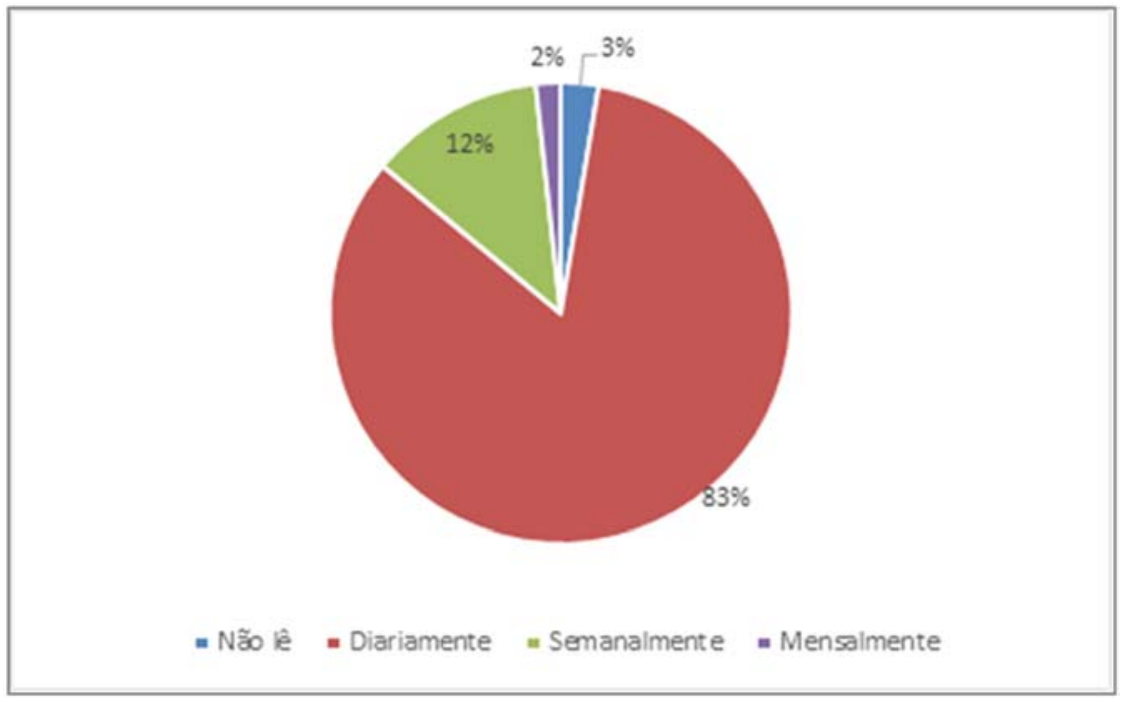

(Fonte: dados da pesquisa)

A leitura de textos na Internet é realizada, de acordo com os dados coletados pelo questionário e apresentados na Figura 3, por 97,0\% dos participantes, dos quais aproximadamente $86,0 \%$ o fazem diariamente $(83,0 \%$ do total). Outros $12,0 \%$ dos participantes leem textos na Internet semanalmente e apenas 2,0\% leem mensalmente este tipo de texto.

Para a análise destes dados é necessário levar em consideração que textos na Internet não são um gênero textual, mas sim uma categoria na qual foram divididos os textos para o presente estudo. Desta forma, os textos aqui mencionados podem ser de diversos gêneros, por exemplo, contos, histórias, poesias, artigos acadêmicos e notícias - que tradicionalmente são publicados em jornais e revistas. Outro fator que deve ser considerado é a difusão do acesso à rede mundial de computadores que aconteceu na última década. A partir do aumento do acesso à Internet, os usuários passaram a ter mais contato com este tipo de texto de forma rápida e gratuita. Estes, dentre outros fatores, colaboram para o crescimento da popularidade desta categoria em estudo.

É importante ressaltar, conforme destacado por Vieira (2015), que a maioria dos textos acessados na Internet não são acadêmicos e nem sempre são confiáveis. Por isso, grande parte dos leitores de textos online se mostram desinformados mesmo após muito tempo de dedicação à leitura destes (BRASIL, 2014). Além disso, como disse Molina (1992), o leitor não é autônomo diante do texto, sendo incapaz de interpretá-lo ou mesmo de criticá-lo, chegando ao ponto 
de "comprar a informação" sem maiores questionamentos. Tal situação foi descrita pela BBC no relatório "The future of news" (O futuro das notícias) da seguinte forma: "Atualmente há mais dados, opiniões e liberdade de expressão, mas é mais difícil saber o que realmente está acontecendo. Embora as pessoas digam que está mais fácil informar-se, elas estão mais incertas sobre os fatos e menos claras a respeito do que significam" (BBC, 2015).

Analisando os resultados de todas as categorias concomitantemente, a Tabela 5 mostra a ordem de popularidade observada.

Tabela 5 - Níveis de popularidade para as categorias estudadas

\begin{tabular}{cr} 
Nível de Popularidade & Categoria \\
\hline $\mathbf{1}^{\circ}$ & Textos da Internet \\
$\mathbf{2}^{\circ}$ & Jornal Impresso \\
$\mathbf{3}^{\circ}$ & Livros e Artigos Acadêmicos \\
$\mathbf{4}^{\circ}$ & Contos e Histórias \\
$\mathbf{5}^{\circ}$ & Poesias \\
$6^{\circ}$ & Biografias \\
$\mathbf{7}^{\circ}$ &
\end{tabular}

Através da análise dos dados, é possível observar que os textos de Internet são os mais populares. Porém, assim como discutido anteriormente, textos de Internet podem compreender uma diversidade grande quanto ao gênero e, desta forma, estarem inclusos dentro das outras categorias consideradas. Um futuro estudo que quantifique e diferencie os tipos de textos lidos na Internet possibilitará a melhor análise destes dados.

Destaca-se também a frequência de leitura das categorias jornal impresso, revistas e livros e artigos acadêmicos. Essas três categorias compreendem gêneros textuais que estão ligados intimamente à informação. Desta forma, é possível destacar que os alunos de engenharia do CAP-UFSJ têm preferência por leituras informativas. Porém, há dois tipos principais de informação relacionados nestas categorias: informações de atualidades (jornais e revistas) e de conhecimento científico (livros e artigos acadêmicos). Não obstante, estes são os principais tipos de informações exigidas de profissionais de engenharia quando estes estão em processo de ingresso no mercado de trabalho. Porém, não é possível afirmar que esta é a preferência dos participantes do presente estudo, pois tal resultado pode refletir apenas o ponto de obrigação disciplinar que, como um fato social coage os estudantes a manterem contato direto com este tipo de leitura. 
Fica evidente a preferência pelos textos informativos, bem como pelo imediatismo da informação - uma vez que textos da Internet figuram em primeiro lugar na tabela de popularidade das categorias analisadas no presente estudo. Tal resultado vai de encontro com a liquefação do mundo contemporâneo proposta por Bauman (2001), segundo o qual o mundo se comporta como fluidos que "não se atêm muito a qualquer forma e estão constantemente prontos a mudá-la" (FRAGOSO, 2011; BAUMAN, 2001). Este foi também observado por um dos docentes na consulta realizada aos professores do CAP - UFSJ, segundo ele, "esta geração está imersa numa realidade relativista, fast food, mensagens curtas, soluções rápidas, poucos caracteres. Tudo isso e muito mais, conduz a geração atual ao imediatismo, a uma cultura rasa e superficial e uma das consequências é a ausência de senso crítico para interpretar adequadamente a realidade na qual essa geração vive". Este relato está em conformidade com os resultados obtidos pela BBC (2015) - comentados anteriormente. Por outro lado, é confortante o fato de que os alunos aprenderam a buscar os tipos de leituras que são mais importantes para o desenvolvimento de uma carreira sólida nas suas respectivas áreas profissionais.

Do outro lado da Tabela 3, as categorias de poesias e biografias apresentam os mais baixos valores de popularidade entre aquelas consideradas neste estudo - ambas apresentam taxas de rejeição acima de 50,0\% dos entrevistados.

A categoria de contos e histórias se encontra abaixo das mais populares (Internet, livros e artigos acadêmicos, jornais impressos e revistas) e acima daquelas mais rejeitadas (poesias e biografias). Esta categoria apresenta características que não são inerentes aos dois extremos da tabela de popularidade, fazendo dela o ponto médio na presente análise. Ao mesmo tempo em que apresenta alto nível de rejeição $(43,0 \%)$, este nível de rejeição não é tão alto quanto às categorias menos populares e a frequência de leitura não é tão alta quanto àquela praticada pelas categorias mais populares, mas não é baixa o suficiente para enquadrá-la nos gêneros marginais ao gosto dos participantes. Por conseguinte, este tipo de gênero textual pode ser considerado de popularidade média dentro do nicho no qual a pesquisa foi realizada.

As demais perguntas apresentadas no questionário (Anexo I) não foram amplamente analisadas no presente estudo por apresentarem resultados de pouco ou nenhum valor quantitativo - uma vez que as respostas obtidas foram muito divergentes. Desta forma, os dados coletados pelo questionário sobre hábitos de leitura realizado no CAP/UFSJ foram analisados diferenciando os participantes e seus respectivos hábitos de acordo com o sexo, curso, escolaridade dos pais, fontes de lazer e tipos de leitura.

\section{Conclusão}

O questionário sobre hábitos de leitura aplicado pelo grupo PET-DPCFC no CAP-UFSJ foi utilizado para a avaliação do interesse dos alunos pela leitura e sua consequente realização dentro do cenário acadêmico. Foi possível verificar que no nicho avaliado, $71,4 \%$ declaram gostar de ler, porém observa-se que esse gosto não se transforma em prática constante. Não foram observadas relações 
discentes do curso de engenharia de telecomunicação são os que mais gostam de ler e os de engenharia civil os que menos gostam.

Percebe-se que as leituras de texto de Internet se destacam no ranking de preferências entre as categorias abordadas. Como levanta o sociólogo Zygmunt Bauman (DINES, 2015), a necessidade de informações cada vez mais rápidas é uma característica da sociedade pós-moderna. Neste contexto, a informação nas redes tem sido fragmentada e mal compreendida. Segundo Bauman (2015) "o Google tem a maior biblioteca do mundo, mas não é a maior biblioteca de livros, é a maior biblioteca de trechos, de citações, de partes e pedaços desconectados". Constitui-se, assim, uma crítica explícita ao sistema fragmentado de absorção de informações. Além disso, este sistema pode ser a causa da percepção em sala de aula de que os alunos não conseguem dar significado ao que leem - conforme foi apresentado por Molina (1992) e discutido na seção anterior.

A principal barreira apontada como empecilho para a realização da leitura foi o tempo gasto nesta atividade. Esta barreira está intimamente ligada à fluidez da sociedade pós-moderna. Tomando-se por base as características apresentadas para a educação nesta sociedade, é possível verificar que se exige cada vez mais imediatismo da informação ao passo em que há baixa capacidade de análise e crítica da mesma (VEIGA-NETO, 2008). Conforme Bernadete (2005), "com a intensificação da fragmentação da realidade social e cultural, desencadeada pelas tecnologias, pela comunicação de massa, pela informação intensa, instantânea e rasa, sem reflexão, resvala-se para uma multiplicidade de sentidos sem sentido e para a perda de referências mais sólidas". Daí pensarmos que a máxima "a pressa é inimiga da perfeição" é precisa e tradutora da atual realidade dos sistemas de leitura, informação e educação.

Os resultados e as conclusões aqui geradas são relativos ao nicho estudado: discentes de engenharia do CAP-UFSJ, no qual, conforme consulta realizada, diversos docentes apontaram a necessidade de intervenções para melhorar as habilidades de leitura, crítica e interpretação textual dos alunos. Outros estudos sobre o tema devem ser realizados para possibilitar a comparação dos resultados com alunos de outras áreas, bem como de áreas semelhantes em outras regiões.

Finalmente, foi possível observar uma grande influência dos costumes e das necessidades de momento nos hábitos de leitura. Além disso, a falta de habilidade para criticar e interpretar não só textos, mas informações de forma geral, não é perceptível àqueles que não possuem tal habilidade justamente pela falta desta perícia. Desta forma, se a universidade é responsável por formar uma massa pensante crítica, é preciso refletir profundamente nesta questão e pensar em intervenções que possibilitem novos caminhos para a preparação dos discentes (RODRIGUES, et al., 2014) bem como sua formação como população crítica capaz de exercer seus direitos e deveres de cidadãos. 


\title{
READING HABITS' STUDY IN THE ACADEMIC COMMUNITY OF THE UNIVERSIDADE FEDERAL DE SÃO JOÃO DEL-REI CAMPUS ALTO PARAOPEBA
}

\begin{abstract}
In postmodernity, functional illiteracy and informational immediatism generate a lack of interpretation and critical skills. These inabilities may be related to low reading quality. Then this study examined reading habits in a sample of 220 students at CAP-UFSJ through a survey. The results showed that $71.4 \%$ enjoy reading (males: 64.5\%; females: $78.2 \%$ ). The courses that like the most and least reading are telecommunications $(77.2 \%)$ and civill $(59.2 \%)$ engineering. There was no significant change in reading habits with the variation of parents' background education and access to the Internet. The frequency of reading styles is: newspapers $(94 \%)$, magazines $(90 \%)$, books/scholarly articles $(86 \%)$, stories $(57 \%)$, poetry $(44 \%)$ and biographies $(43 \%)$. Internet articles and lack of time for reading were noteworthy. Therefore, reading with low quality, generated by the postmodern fluidic pressure, reflects the poor capacity of information and education. Wherefore, interventions capable of modifying the observed facts are needed.
\end{abstract}

KEYWORDS: reading comprehencion, engineering, habits' study. 


\section{REFERÊNCIAS}

BBC. Future of news. Londes: BBC, p. 47, 2015.

BAUMAN, Zygmunt. Modernidade líquida. Rio de Janeiro: Jorge Zahar Ed., p. 258, 2001.

BAUMAN, Zygmunt. Fragmentação das informações. Rio de Janeiro, Observatório da Impresa, 16 out. 2015. Entrevista a Alberto Dines.

BERNARDETE, A. Pesquisa, educação e pós-modernidade: confrontos e dilemas. Cadernos de Pesquisa, São Paulo, v. 35, n. 126, p. 595-608, set/dez, 2005.

BRASIL. Presidência da República. Secretaria de Comunicação Social. Pesquisa Brasileira de Mídia 2015: hábitos de consumo de mídia pela população brasileira. Brasília, Selecon: 2014. 153 p.

DINES, A. Entrevista com Zygmunt Bauman. Observatório da Impresa, Rio de Janeira, prog. 170, out, 2015.

CANABRAVA, T.; VIEIRA, O. F. A. Treinamento e desenvolvimento para empresas que aprendem. Brasília: Senac, 2006. 9 p.

CRISTOFOLINE, C. Refletindo sobre a provinha Brasil a partir das dimensões sociocultural, linguística e cognitiva da leitura. Alfa, São Paulo, v. 56, n. 1, p. 217247, 2012.

EUGÊNIO, M.; ESCALDA, J.; LEMOS, S. Desenvolvimento cognitivo, auditivo e linguístico em crianças expostas à música: produção de conhecimento nacional e internacional. Rev. CEAFC, São Paulo, v. 14, n. 5, p. 992-1003, set/out, 2012.

FRAGOSO, T. Modernidade líquida e liberdade consumidora: o pensamento crítico de Zygmunt Bauman. Rev. Perspectivas Sociais, Pelotas, v. 1, n. 1, p. 109124, mar, 2011.

GUIMARÃES, J. Biblioteca escolar e políticas públicas de incentivo à leitura: de museu de livros a espaços de saber e leitura. 2010. 116 f. Dissertação (Mestrado em Educação) - Faculdade de Ciências e Tecnologia, Universidade Estadual Paulista, Presidente Prudente, 2010.

INSTITUTO PAULO MONTEIRO; ONG AÇÃO EDUCATIVA. Indicador de alfabetismo funcional: Brasil 2011. São Paulo: IPM. 2012. 25 p.

LÚCIO, P.; PINHEIRO, A.; NASCIMENTO, E. do. A influência de fatores sociais, individuais e liguísticos no desempenho de crianças na leitura em voz alta de palavras isoladas. Psicologia: Reflexão e Crítica, Porto Alegre, v. 23, n. 3, p. 496505, 2009.

MOLINA, O. Ler para aprender: desenvolvimento de habilidades de estudo. São Paulo: EPU, 1992. 109 p. 
OLIVEIRA, M. de. Funções da leitura para estudantes de graduação. Psicologia Escolar e Educacional, Maringá, v. 1, n. 1, p. 61-68, 1996.

PICCOLO, L.; FALCETO, O.; FERNANDES, C.; LEVANDOWAKI, D.; GRASSI-OLIVEIRA, R.; SALLES, J. Variáveis Psicossociais e desempenho em leitura de crianças de baixo nível socioeconômico. Psicologia: Teoria e Pesquisa, Brasília, v. 28, n. 4, p. 389-398, out/dez, 2012.

VEIGA-NETO, A. Crise da modernidade e inovações curriculares: da disciplina para o controle. In: ENCONTRO NACIONAL DE DIDÁTICAS E PRÁTICA DE ENSINO, 14., 2008, Curitiba. Artigos. São Paulo: ENDIPE, 2008, p 38-58.WELLINGTON, J.; OSBORNE, J. Language and literacy in science education.Buckingham e Philadelphia: Open University Press, 2001. 153 p.

RODRIGUES, M.; ALVEZ, M.; ALMEIDA, R.; SILVA, R. DA. Intervensão em habilidades cognitivas e metacognitivas de leitura em alunos do Programa de Educação Tutorial - PET. Psicologia: Teoria e Prática, Brasília, v. 16, n. 1, p. 181190, jan/abr, 2014.

VIEIRA, L. Por que o jornalismo online ainda é pouco confiável? Observatório da Impressa, São Paulo, ed. 848, abr, 2015.

WELLINGTON, J.; OSBORNE, J. Language and literacy in science education. Buckingham e Philadelphia: Open University Press, 2001. 153 p.

YORE, L.; HAND, B.; FLORENCE, M. Scientists' views of science, models of writing, and science writing practices. Journal of research in science teaching, Malden, $v$. 41, n. 4, p. 338-369, 2004.

YUNES, E. Pensar a leitura: complexidade. Rio de Janeiro: PUC - Rio; São Paulo: Loyola, 2002. 184 p.

Recebido: 2016-08-22

Aprovado: 2017-10-24

DOI: $10.3895 /$ rbect.v10n3.4551

Como citar:

OLIVEIRA, M.C.A.; MOREIRA, E.; GONCALVES, R.; TOLEDO,G.L.; FABRINO.D.L. Estudo dos hábitos de

leitura na comunidade acadêmica do Campus Alto Paraopeba da Universidade Federal de São João del-Rei.

Revista Brasileira de Ensino de Ciência e Tecnologia, v. 10, n. 3, 2017. Disponível em:

<https://revistas.utfpr.edu.br/rbect/article/view/4551>. Acesso em: xxx.

Correspondência:

Mateus Chaves Almeida de Oliveira mateus.chaves@yahoo.com.br

Direito autoral: Este artigo está licenciado sob os termos da Licença Creative Commons-Atribuição 4.0 Internacional. 


\section{ANEXO}

O questionário aplicado junto a 220 alunos divididos igualmente entre os cinco cursos de engenharia do CAP/UFS é apresentado nas Figuras A1 e A2.

Figura A1 - Primeira página do questionário

PET-Difusão do Pensamento Cientifico como Ferramenta para Cidadania

\section{QUESTIONÁRIO SOBRE HÁBITOS DE LEITURA- GrUPO CAP Leitura}

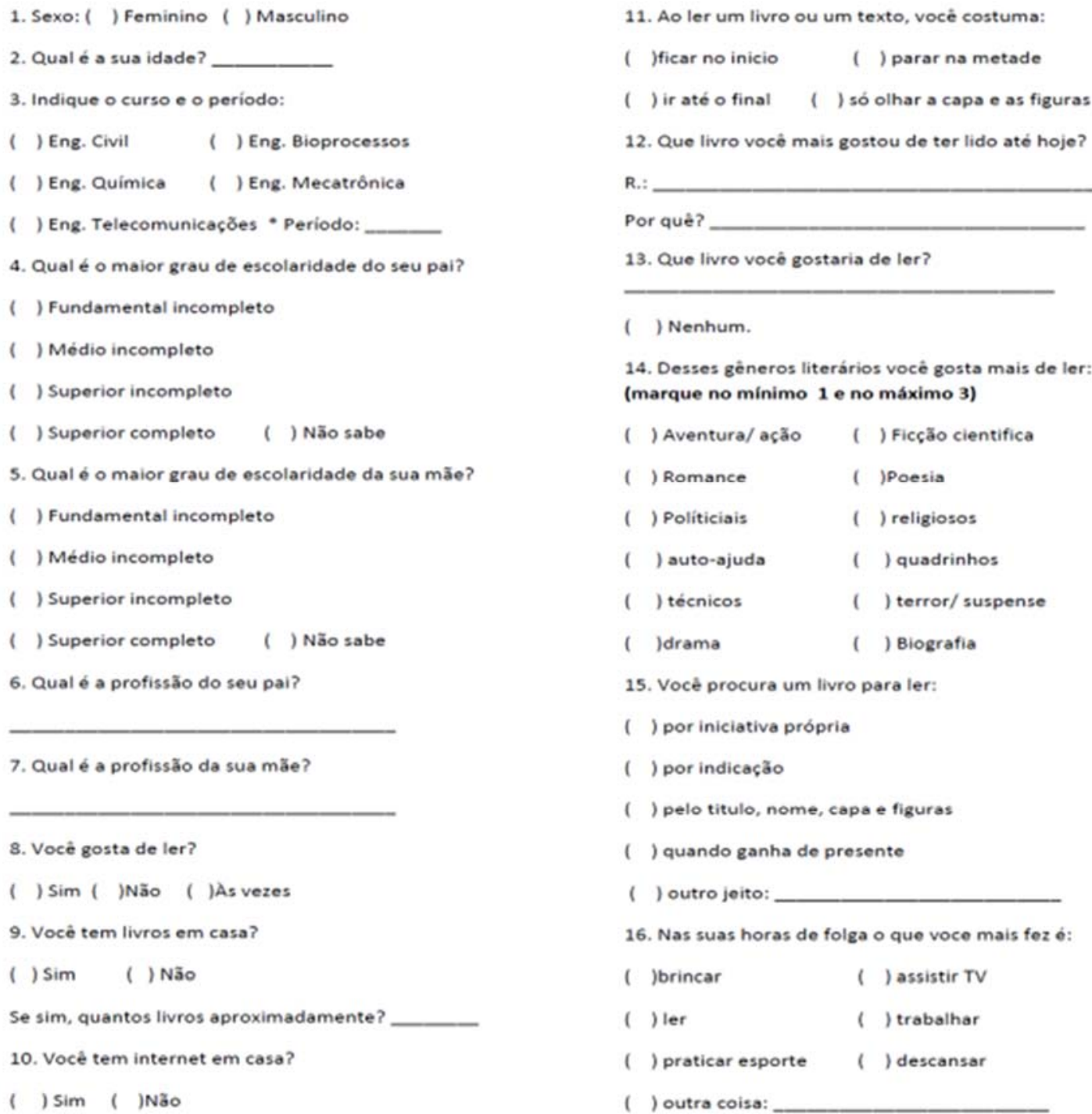

(Fonte: dados da pesquisa) 
Figura A2 - Segunda página do questionário

PET-Difusão do Pensamento Científico como Ferramenta para Cidadania

Dopextot

17. ASSINALE COM "X" QUANTO VOCE LÊ OS MATERIAIS ABAIXO:

\begin{tabular}{|l|l|l|l|}
\hline & DIARIAMENTE & SEMANALMENTE & MENSALMENTE \\
\hline Contos/histórias & & & \\
\hline Jornal & & & \\
\hline Revistas & & & \\
\hline Poesias & & & \\
\hline Biografias & & & \\
\hline $\begin{array}{l}\text { Livros/Artigos } \\
\text { acadêmicos }\end{array}$ & & & \\
\hline $\begin{array}{l}\text { Textos na } \\
\text { Internet }\end{array}$ & & & \\
\hline
\end{tabular}

18. Como tem acesso a livros?

() Biblioteca ( ) Emprestado de amigos

( ) Internet ( ) Compra

( ) outro

19. Você costuma comprar livros?

( ) Sim, de 1 aे 3 por ano

( ) Sim, de 4 à 8 por ano

( ) Mais de 8 por ano

( ) Não, por que?

20. Quais são as maiores barreiras para a sua frequência na leitura?

( ) Tempo ( ) Condições financeiras

( ) Dificuldade uso/acesso da biblioteca

( ) lentidão da leitura

( )outro

21. Conhece o grupo de leitura do CAP?

( ) sim ( ) não
22.Se conhece por que não foi ao grupo?

( ) Data ruim

( )Horário Ruim

( )Livro ruim

( ) falta de interesse

( ) não se sente a vontade com as pessoas do grupo

(Fonte: dados da pesquisa) 